\title{
Empirical Model of a Human Body Resistance at a Hand-to-Hand DC Flow
}

\author{
Sergiusz Boron ${ }^{1}$, Adam Heyduk ${ }^{1}$, Jarosław Joostberens ${ }^{1}$, Joachim Pielot ${ }^{1}$ \\ ${ }^{I}$ Department of Electrical Engineering and Control in Mining, Faculty of Mining and Geology, \\ Silesian University of Technology \\ Akademicka 2A St. 44-100, Gliwice, Poland \\ sergiusz.boron@polsl.pl
}

\begin{abstract}
In recent times the areas of application of direct current systems are being expanded. This may lead to increased risk of electric shock. The subject of investigations described in this paper is a non-linear model of the resistance of the human body under the conditions of direct current electric shock. The aim of the study was to determine the approximate model of the human body resistance at a hand-to-hand DC flow, which may be useful for assessing the effects of the electric shock. The investigations were carried out on three subjects using the hand to hand current path. Experimental studies were conducted within a voltage range of up to $80 \mathrm{~V}$, while the analytical form of the identified model enables extrapolation of the obtained results to a wider range of touch voltages. The identified models allow to evaluate the shock hazard within a voltage range of up to $1500 \mathrm{~V}$. The adopted shock hazard criterion was the probability of ventricular fibrillation of $5 \%$. The result of the studies was a direct correlation between maximum allowable duration of shock and the touch voltage determined for the three subjects on the basis of the relationship between shock duration and the touch current specified in the IEC report, and of non-linear models of resistance identified on the basis of experimental studies. It was demonstrated that for touch voltages of up to $650 \mathrm{~V}$ the fibrillation phenomenon should not occur when the shock duration is shorter than 10 seconds.
\end{abstract}

Index Terms-Electric shock; resistance of the human body; fibrillation.

\section{INTRODUCTION}

The effect of direct current on the human being is less harmful than that of alternating current. Moreover, the number of direct current electric shock incidents is much lower than that of alternating current incidents, which is due to the much smaller number of appliances and devices powered by direct current. However, direct current applications are increasing and becoming available to users lacking appropriate qualifications, and therefore the hazard of direct current shocks is rising.

A decision to switch from DC to AC supply systems was taken in USA in 1880 [1]; since that time the alternating current is the dominating mode of supplying power to electrical equipment. Recently, however, the applications of direct current are growing in terms of both their number as well as their diversity.

Electrical energy sources include galvanic cells and

Manuscript received 13 December, 2015; accepted 28 March, 2016. rechargeable (secondary) cells. Photovoltaic cells are used in solar power stations, hybrid vehicles, automatic control systems [2]. Photovoltaic systems for supplying power to single-family homes are integrated with the roofs and facades of such houses [3], which may pose an increased risk of electric shock.

Electronic power converters are devices of many different applications. These systems serve to transfer electrical energy between circuits differing in frequency, voltage or current. Electronic power converters include direct (or rectified) current circuits. Converters are divided into: rectifiers, DC-DC converters (these are the basic pulse stabilizer systems), AC-DC converters, AC-AC converters with DC intermediate circuit (frequency converters), DC-AC converters (inverters) [4].

Most DC motors are supplied from 6-pulse rectifiers, often from 12-pulse rectifiers [1]. Permanent magnet DC (PM BLDC) motors find growing use in the industry and in vehicles [5], [6].

Alternating current motors are often powered by frequency converters with DC intermediate circuit (in the Polish underground mines these include cables hundreds of metres long).

Many authors list numbers of various applications of industrial DC voltages: $125 \mathrm{~V}-250 \mathrm{~V}$ [7]-[10], $575 \mathrm{~V}-$ $600 \mathrm{~V}$ (mainly DC motors) and $600 \mathrm{~V}, 1200 \mathrm{~V}, 1500 \mathrm{~V}$, $3 \mathrm{kV}$ in electric traction.

The supply system of a railway electric traction includes hundreds of thousands of traction network lines and thousands of facilities: substations and sectioning cabins. In Poland a $3 \mathrm{kV}$ DC system is and will be used. Direct current systems $(3 \mathrm{kV}$ and $1.5 \mathrm{kV})$ are also used in other European countries [11]. The tramway and trolleybus traction in Poland is supplied with $600 \mathrm{~V} \mathrm{DC}$ voltage, and the traction in underground mines with $250 \mathrm{~V}$ DC.

In 1954 the first high-voltage direct-current (HVDC) system was used to transmit electric power. Today the total transmission capacity is over $30 \mathrm{GW}$.

One important group of direct current applications are systems for providing uninterruptible power supply (UPS) to safety-critical equipment, such as that used in operating theatres. UPS systems comprise a rectifier, rechargeable cell or a battery of cells, and an inverter [6], [7], [12].

Many low power devices, such as personal computers, 
telephones, printers, copying machines and other equipment running on single-phase current for use at homes are powered from transformerless power supplies, which are small, lightweight and efficient [1].

At present, direct current is often used in lighting applications. High current (350 mA) LEDs are powered with a DC voltage of less than $100 \mathrm{~V}$ or from a rectifier connected directly to an alternating voltage of from $90 \mathrm{~V}$ to $265 \mathrm{~V}$ [13]. Manufacture of lamps and devices that use constant voltages of several tens or hundreds of volts requires great attention to be attached to the quality of insulation, the more so as such equipment is used increasingly, also for medical applications, e.g. in operating theatres [13]. Neon lamps may also be powered by DC voltage of $105 \mathrm{~V}$ to $125 \mathrm{~V}$ [7].

Recently a number of issues have been raised in connection with operating safety of systems and equipment (such as effective protection of direct-current circuits in frequency converters). In addition, mass production of devices and appliances designed for use by people with no qualifications, including children, justifies the undertaking of a wide scope of studies on direct current shocks. This paper presents the results of a fragment of such studies. During future studies the authors intend to determine the parameters of a human body during the passage of rectified currents, and later on of currents of various waveforms, with various content of higher harmonics.

Effects of DC touch current on a human being are presented in Section II. Section III characterizes human body impedance models, and Section IV describes the conditions under which the authors of this paper conducted their investigations. Measurement results along with their interpretation are given in Section $\mathrm{V}$.

\section{EFFECT OF Direct CURRENT ON A HUMAN BEING}

The effects of an electric shock depend on the value of the touch current, duration of the shock, current pathway through the body, type of current (direct, alternating) and its frequency and on physiological characteristics of the individual. The value of the touch current depends on the touch voltage and impedance of the shock circuit, wherein the impedance of the body plays an important role. Due to the lower number of devices and systems powered with direct current (as compared to alternating current) under voltages capable of producing adverse effects, the direct current shock incidents are much less frequent than those involving alternating currents, and they constitute only a few percent of the overall number of electric shock accidents [14]. Fatal direct current electric shocks usually take place under adverse environmental conditions which are conducive to low resistance of the shock circuit (e.g. in underground mines). Low mortality in DC shocks also stems from better let-go conditions and higher (during longer shock duration) threshold value of fibrillation current than in the case of $50 \mathrm{~Hz}$ or $60 \mathrm{~Hz}$ alternating current. The reason for this is that the stimulation of nerve and muscle reaction requires a certain rhythm of changes of the shock current. Direct current is felt by humans only during switching on and off of the shock current. Constant flow of direct current is accompanied by much less noticeable reactions. Threshold of direct current perception is from $1.5 \mathrm{~mA}$ to $2.5 \mathrm{~mA}$ (during a slow increase of direct current the perception limit is practically imperceptible). Similarly, the let-go current, ranging from $25 \mathrm{~mA}$ to $70 \mathrm{~mA}$, is determinable only when the direct current is switched on and off. With pulses of current higher than the let-go threshold lasting for several seconds or several minutes, overcoming muscle contractions may prove impossible. In the case of transverse direct current shock (e.g. from left hand to right hand), the occurrence of ventricular fibrillation is unlikely. Nevertheless, when such shock is sustained for a long time, high shock currents may lead to reversible cardiac arrhythmia, burns and loss of consciousness, which in the absence of appropriate medical aid can result in death. Ventricular fibrillation with DC shocks usually occurs in the case of longitudinal current flow in the body. The value of the threshold shock current that causes fibrillation is two times higher for downward currents (negative potential of feet) than for upward currents. According to the IEC report [15], with shocks lasting more than $0.2 \mathrm{~s}$, the value of the direct current liable to cause fibrillation is much higher (almost fourfold) than that of an alternating current and is equal to $150 \mathrm{~mA}-200 \mathrm{~mA}$. Effects of electric shock caused by direct current flow of short duration do not differ from those caused by alternating current.

It should be noted that while even a prolonged passage of alternating current of a value lower than the threshold of perception does not produce adverse effects, in the case of direct current an electrolytical action may occur leading to pathological alterations. These alterations depend on shock duration and on the value of the touch current. The passage of direct current through electrolytes contained in the tissues causes sodium and chlorine ions to move and consequently results in the evolution of free hydrogen and sodium hydroxide, the action of which leads to tissue necrosis. There are known cases of electric shocks from DC power traction, when death occurred only after several days as the result of blood electrolysis.

In addition to direct pathophysiological effects of electric shock, there are effects of constant electric and magnetic fields on the human body. Although electric and static magnetic fields are not classified as carcinogenic, this is only due to the lack of evidence for such effects [16].

\section{Selected Models of Human Body IMPEDANCE}

Various models of human body impedance have been developed and described in the literature [15], [17]-[19]. The model of human body impedance given in the IEC 4791 report is shown in Fig. 1(a). It consists of a series connection of skin impedances $\left(Z_{p 1}, Z_{p 2}\right)$ and of internal impedance $Z_{i}$. Skin impedance is the function of touch voltage, frequency and current passage duration. It also depends on skin humidity, temperature, type and kind of skin, contact surface area and contact pressure [15]. The internal impedance of the human body largely depends on the current pathway, while the contact surface area affects it to a much lesser extent [14], [15]. In the model proposed by W. Korniluk [18], [19], the skin impedance is a combination 
of two skin resistances $\left(R_{c}, R_{n}\right)$ and of the capacitance of epidermis $C_{p}$. In that model, the impedance of the internal part of the human body $Z_{i}$, at shock currents with frequencies of up to $10 \mathrm{kHz}$, is essentially equivalent with resistance $R_{i}$ [19]. In the case of electric shock with a current frequency higher than $10 \mathrm{kHz}$, the equivalent circuit is complemented with capacitance $C_{i}$ (Fig. 1(b)).

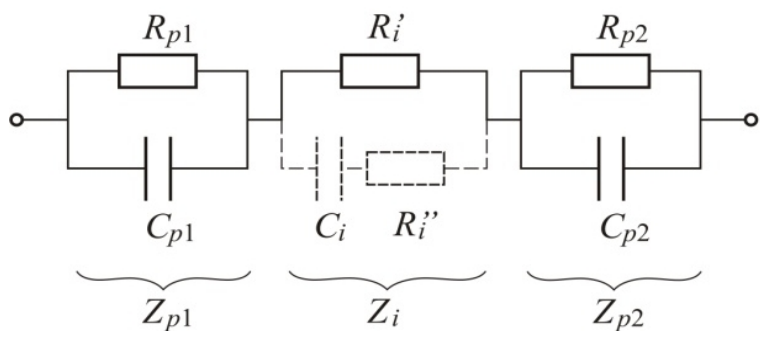

a)

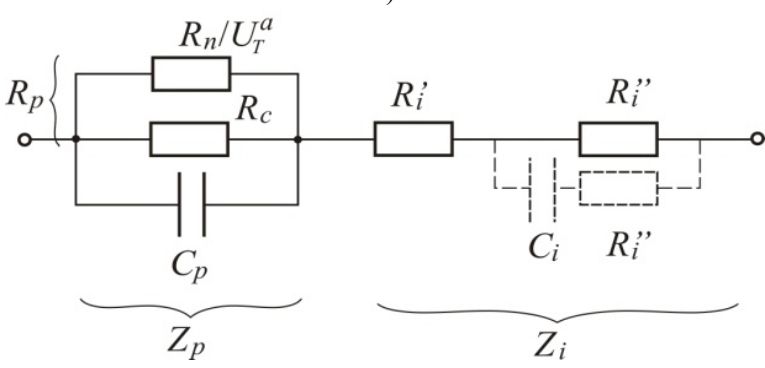

b)

Fig. 1. Equivalent circuit of human body impedance: a) given in the IEC 479-1 report, b) proposed by W. Korniluk.

In the steady state, and at frequencies of up to $100 \mathrm{~Hz}$, the internal impedance of the human body may, in essence, be regarded as resistance $R_{i} \approx Z_{i}$ [15]. Reference [15] also tells of initial resistance of the human body $\mathrm{R}_{o}$, which is approximately equal to the internal resistance. The total resistance of a body when subjected to a direct current shock is higher than the total impedance in case of alternating current and at rms value of touch voltages lower than $150 \mathrm{~V}$, as under such conditions the effect of capacitive reactance of the skin is significant.

\section{EXPERIMENTAL CONDITIONS}

The study was conducted on three male subjects by performing a series of measurements in accordance with the requirements of the standard method of resistance measurement, as verified in accordance with the rules of mathematical statistics and accepted for electrophysiological studies [17], [18]. The current pathway adopted in the studies was from hand to hand with large contact surface area (that of open palms of hands). To ensure direct current passage along the mentioned pathway, the subjects wore footwear with insulating soles. In addition, during the measurements the subjects stood on an electrical insulating matting. The measured shock currents along the hand to hand path did not exceed $10 \mathrm{~mA}$.

Resistance was determined using the ammeter-voltmeter method. Voltages and currents were measured by means of digital meters. In order to ensure comparable measurement conditions related to the human hand pressure applied to the electrodes, a digital balance was used. The direct current source consisted of laboratory power supplies connected in series to provide a maximum total voltage of $100 \mathrm{~V}$ with adjustable current limit.

The statistical representation of the relationship between human body impedance and touch voltage has been widely described in the literature [15], [18], [19]. Empirical models developed on the basis of test results enable quantitative assessment of the relationship between the human body resistance and the touch voltages, which is important in assessing the possible effects of a shock current when using DC powered electrical equipment. In order to determine the resistance of a human body, a human body impedance model was used the equivalent circuit of which is shown in Fig. 2. As can be seen, this model is a simplified version of the one proposed by Korniluk.

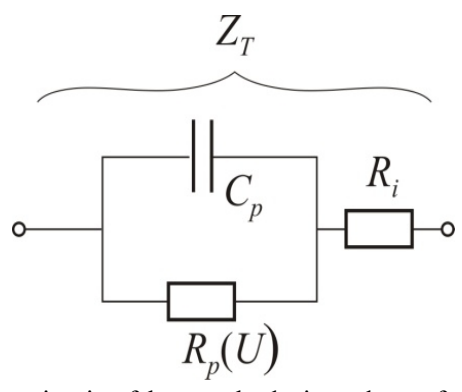

Fig. 2. Equivalent circuit of human body impedance for a direct current hand to hand path used in the studies.

The model adopted for the mathematical description of the relationship between the human body resistance and the touch voltage had the following form

$$
R_{T}=r_{T} \times U_{T}^{a}+R_{i}
$$

where $R_{T}$ - resistance of the human body [k $\left.\Omega\right], U_{T}$ - touch voltage $[\mathrm{V}], r_{T}-$ coefficient $\left[\mathrm{k} \Omega / \mathrm{V}^{\mathrm{a}}\right], a-$ exponent.

As shown in [20], the internal resistance $R_{i}$ of the human body (equivalent to the initial resistance $R_{o}$ ) amounts to $780 \mathrm{k} \Omega \pm 114 \mathrm{k} \Omega$. For this reason, the total resistance model parameters for the individual subjects for the hand to hand current path described by (1) were determined while allowing for internal resistance variation within the specified range and adopting the boundary confidence level. As a measure of goodness of fit of the model to empirical data, a residual variance was adopted, defined as

$$
\sigma_{j}^{2}=\frac{1}{N_{j}-1} \sum_{k=1}^{N_{j}}\left(R_{T j}-\hat{R}_{T j}\right)^{2}
$$

where $R_{T j}$ - measured body resistance along the hand to hand path of $j$-th subject $[\mathrm{k} \Omega], \hat{R}_{T j}$ - body resistance along the hand to hand path of $j$-th subject expected under the model [k $\Omega], N_{j}$ - number of measurement data used to determine model parameters.

Parameters of the model of form (1) for the $j$-th subject will be determined correctly when the residual variance (2) reaches a minimum value. This task involves adopting parameters $R_{T}, r_{T}$ and $a$ of (1) that minimize the criterion expressed by (2), which can be written down as follows

$$
\left(\hat{r}_{T j}, \hat{R}_{i j}, \hat{a}_{j}\right)=\min \left\{\sigma_{j}^{2}\right\} .
$$




\section{RESULTS AND INTERPRETATION}

The measurement results are presented graphically in Fig. 3. Based on the measurement data (Fig. 3), total human body resistances were determined for the individual subjects, and the results obtained are shown in Fig. 4.

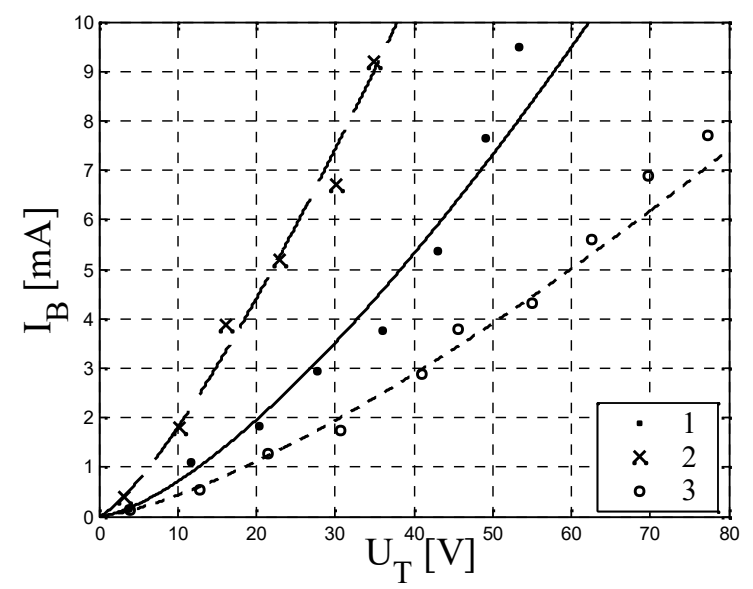

Fig. 3. Measurement data shown against the background of curves plotted in accordance with the empirical model of human body resistance along the hand to hand direct current path.

The determined values of (1) parameters are listed in Table I, and the curves describing the relationship between the resistance of the individual subjects along the hand to hand current path and the touch voltage are shown in Fig. 4.

TABLE I. IDENTIFICATION RESULTS OF HUMAN BODY RESISTANCE MODEL.

\begin{tabular}{|c|c|c|c|c|}
\hline Subject & $\begin{array}{c}\mathbf{r}_{\mathbf{T}} \\
{\left[\mathbf{k} \boldsymbol{\Omega} / \mathbf{V}^{\mathrm{a}}\right]}\end{array}$ & $\mathbf{a}$ & $\begin{array}{c}\mathbf{R}_{\mathbf{i}} \\
{[\mathbf{k} \boldsymbol{\Omega}]}\end{array}$ & $\begin{array}{c}\boldsymbol{\sigma}^{\mathbf{2}} \\
{\left[(\mathbf{k} \boldsymbol{\Omega})^{2}\right]}\end{array}$ \\
\hline 1 & 43.212 & -0.517 & 1.122 & 1.911 \\
\hline 2 & 10.711 & -0.382 & 1.122 & 0.146 \\
\hline 3 & 55.060 & -0.381 & 0.438 & 1.753 \\
\hline
\end{tabular}

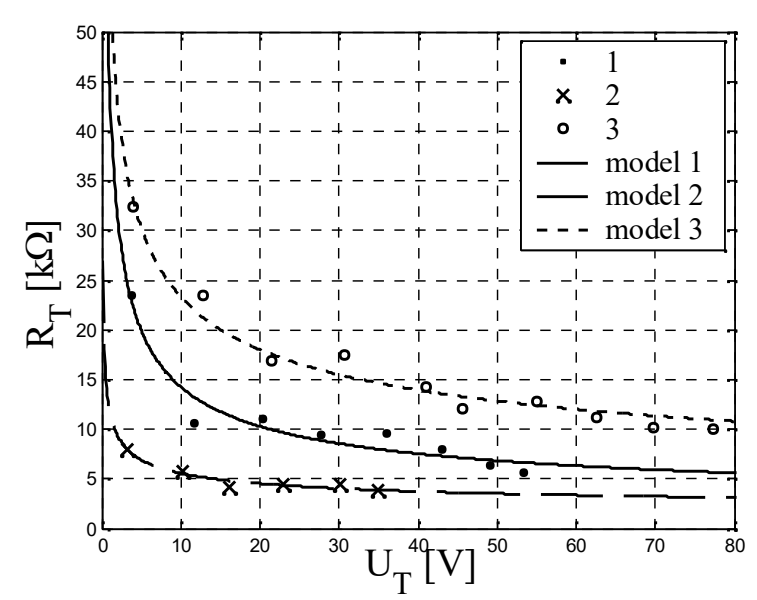

Fig. 4. Resistance values determined on the basis of measurement data and identification results of the relationship between human body resistance along the hand to hand path and the touch voltage for three subjects.

As can be seen in Fig. 4, the determined models of resistance values for the individual subjects show good fit to experimental data. The determined values of internal resistance reached maximum values in the adopted range of variability of this parameter in the case of subjects 1 and 2, and a minimum value in the case of subject 3 , as for these values $R_{i} \approx R_{o}$ and the criterion (2) had the lowest value. However, the criterion (2) attained a minimum for values outside the range of human body internal resistance variation adopted for the tests, and specified in [20].

The relationships between resistance along the hand to hand path of the individual subjects and the touch voltage were extrapolated to a voltage of $1.5 \mathrm{kV}$, assumed to be the highest value of the DC voltage regarded as low. These relationships are shown in Fig. 5. This procedure allows determination of the shock currents at touch voltages higher than those applied during measurements.

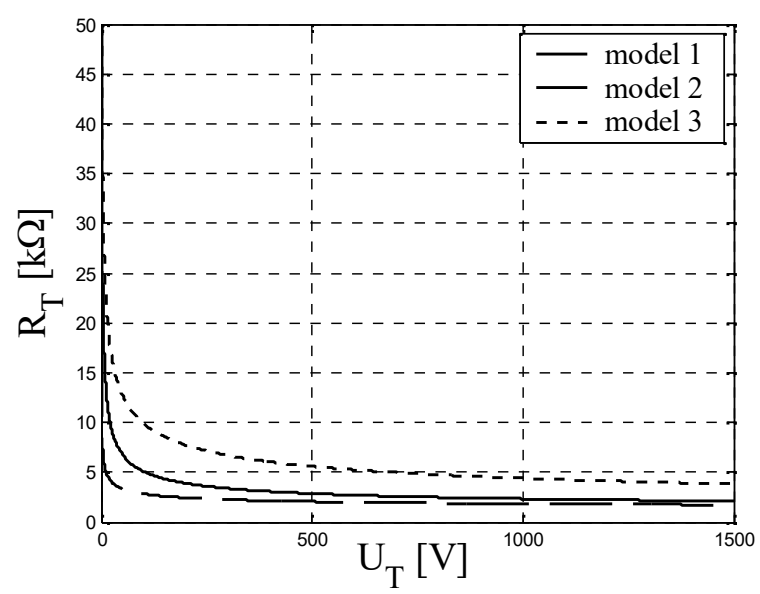

Fig. 5. Human body resistance along the hand to hand path vs. touch voltage plotted for three subjects and extrapolated to the voltage of $1500 \mathrm{~V}$.

The models determined were used to plot curves of shock current vs. touch voltage, as shown in Fig. 3 and Fig. 6. As can be seen in Fig. 3, the curve plotted in this way shows good fit to measurement data.

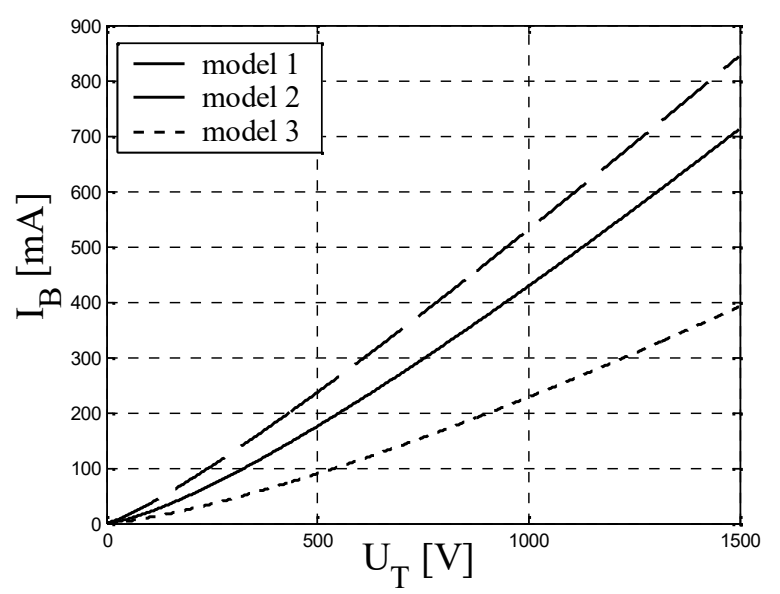

Fig. 6. Relationship between shock current and touch voltage determined from human body resistance models for three subjects along the hand to hand current path.

The IEC 479-1 report specifies time/current zones of the effects of alternating currents $(15$ to $100 \mathrm{~Hz})$ and of direct currents passing along the left hand to both feet path. In the case of alternating shock current flowing along a different path than the left hand to both feet path, it is possible to approximately evaluate the risk of ventricular fibrillation by applying a heart current factor $F$, the values of which for various shock current paths are given in [14]. The heart current factor $F$ is the ratio of current passing through the body along the left hand to both feet path to the current which passes along a different path and represents the same danger of fibrillation. In the case of direct shock currents, 
the so-called equivalence factor $k$ is defined as the ratio of direct current to the equivalent rms value of alternating current, these currents providing the same probability of causing ventricular fibrillation [14]. For shock durations longer than $200 \mathrm{~ms}$, the $k$ factor is equal to 3.75 , for shorter durations it is equal to 1 . The time/current zones of the effects of direct currents, also included in [14], are shown in Fig. 7.



Fig. 7. The time/current zones of the effects of direct current passing along the feet to left hand path (upward current).

The $c_{1}, c_{2}, c_{3}$ curves determine the probability of ventricular fibrillation. In the area between curves $c_{1}-c_{2}$ the probability of ventricular fibrillation is $5 \%$, between curves $\mathrm{c}_{2}-\mathrm{c}_{3}$ that probability is ca. $50 \%$, and above curve $\mathrm{c}_{1}$ it is more than $50 \%$. As reported in [14], for long-term current passing from the left hand to both feet (downward current), these curves should be shifted towards higher current values by a factor of 2 .

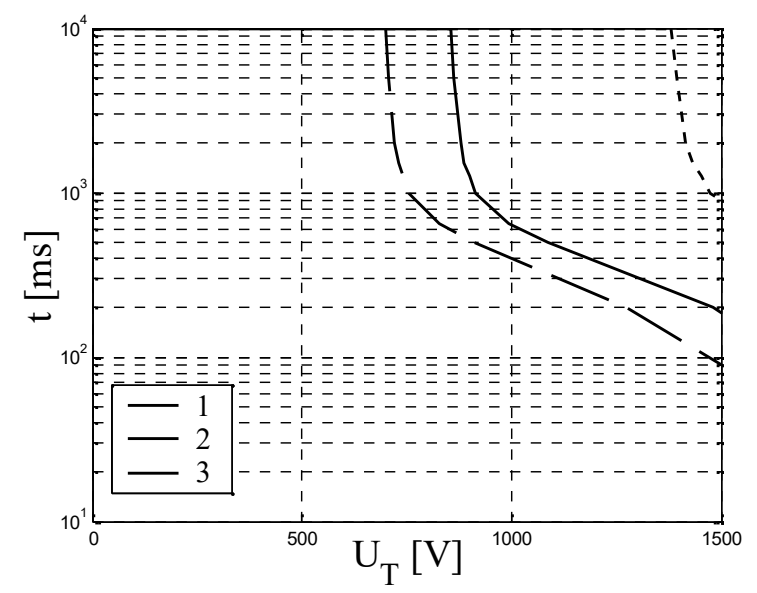

Fig. 8. Approximate relationship between maximum shock duration and expected touch voltages for direct shock current passing along the hand to hand path and liable to cause ventricular fibrillation plotted for the three subjects.

In order to assess the possibility of ventricular fibrillation in the case of hand to hand direct current path, the heart current factor $F=0.4$ was applied to convert the shock currents determined for the hand to hand path to an equivalent (in terms of its effects) current passing from the left hand to two feet (upward current). Knowing the relationship between time and the shock current that does not yet induce ventricular fibrillation (curve $c_{1}$ with heart current factor $F=0.4$ applied), and the expected shock currents in a particular system, it is possible to derive a relationship between the expected maximum shock duration $t$ and the touch voltage $U_{T}$ for a specific person. Graphic representation of these relationships is shown in Fig. 8.

Because of the large contact surface areas, changes in the human skin dependent on current density and current flow duration were not taken into account when deriving the relation $t=f\left(U_{T}\right)$ for the three subjects (in accordance with [14]). The curves shown in Fig. 8 enable estimating electric shock duration times that do not yet cause ventricular fibrillation, and therefore are not life-threatening, in a situation of a shock resulting from touching with both hands by a particular person of two items with a potential difference between them equal to the touch voltage $U_{T}$. The curves shown in Fig. 8 indicate that under conditions similar to the situation of measuring voltages of up to ca. $650 \mathrm{~V}$, the passing of the shock current along the hand to hand path should not induce ventricular fibrillation in any of the subjects within the time of up to 10 seconds. In the case of a higher expected touch voltage, the shock duration times after which ventricular fibrillation could occur, are different for each of the subjects. The results obtained are quantitatively related to laboratory conditions that prevailed when the experiments were carried out. However, both the resistance model, as well as the curves in Fig. 5, Fig. 6 and Fig. 8, will not change significantly under different conditions. In the case of curves in Fig. 8, altering the conditions will cause the curves to shift to the left or to the right.

\section{CONCLUSIONS}

Empirical studies have shown that the resistance of the human body along hand-to-hand current path can be modeled using the impedance model proposed by Korniluk [18]. The analytical form of the proposed model can be presented in the form of (1). The models of human body resistance developed on the basis of empirical studies for three subjects exhibit a good fit to measurement data and in qualitative terms these models are similar to each other. Quantitative differences between the individual models largely result from physiological characteristics of the individuals. It is more difficult to interpret the differences in the values of internal resistance between the various models, and the values of this parameter themselves, which for the individual subjects attained extreme values within the adopted range of possible variations. It should be noted that lower values of criterion (2) were attained for internal resistance outside of the adopted range of variations: it was higher for subjects 1 and 2, and lower for subject 3. This situation resulted primarily from the limitation of the permissible shock current, and consequently also the touch voltage adopted for the tests. Such limitation was adopted for safety reasons. The developed human body resistance models enabled determination of the shock currents passing along the hand to hand path at DC touch voltages greater than those applied during the tests. This in turn allowed to derive a direct relationship between the maximum shock duration and the touch voltage for the three subjects. These graphs enable determination of the expected effects of direct current passage based only on the knowledge of the expected 
shock duration and of the readily determinable touch voltages without the need to determine the value of the shock current along the hand to hand path. The basic criterion for evaluating the hazard was the probability of ventricular fibrillation. The results obtained confirm that ventricular fibrillation is relatively unlikely in the case of direct current passage along the hand to hand path. It must, however, be borne in mind that there may be other health or life threatening effects.

\section{REFERENCES}

[1] R. C. Dugan, et al., Electrical Power Systems Quality. McGraw-Hill: New York, 2003, pp. 9, 185, 191-193, 317, 380, 382.

[2] Poradnik Inzyniera Elektryka, vol. 3, Wydawnictwa NaukowoTechniczne, Warszawa, 2011, pp. 84, 86-88, 552-558. (in polish)

[3] M. Lipinski, Pozyskiwanie energii elektrycznej ze slonca. Wydawnictwo IGSMiE: Krakow, 1998, p. 17. (in Polish).

[4] K. Gorecki, Uklady przetwarzania energii elektrycznej w elektronice. Akademia Morska: Gdynia, 2009, pp. 12-19, 99. (in Polish)

[5] K. Krykowski, Silniki PM BLDC. Wlasciwosci, sterowanie, aplikacje, Wydawnictwo BTC, Legionowo, 2015. (in Polish)

[6] N. Sclater, Handbook of Electrical Design Details. McGraw-Hill, New York, 2003, pp. 55-56, 371-373, 384-387.

[7] T. Croft, F. Hartwell, W. I. Summers American Electricians' Handbook, McGraw-Hill Professional Publishing, 2008, pp. 3.2-3.3, 3.14, 4.141.-4.188, 6.27, 7.2-7.32, 7.62-7.72, 10.80-10.81.

[8] H. W. Beaty, Handbook of Electric Power Calculations. McGrawHill: New York, 2001, pp. 3.2-3.23, 18.2-18.36.
[9] A. Pressman, K. H. Billings, T. Morey, Switching Power Supply Design. McGraw-Hill: New York, 2009, pp. 103-113, 161-171, $545-558,715-722,747-769$.

[10] K. H. Billings, T. Morey, Switchmode Power Supply Handbook. McGraw-Hill: New York, 2011, pp. 1.55-1.57, 1,71-1.75, 1.77-1.84, $1.98-1.99,1.128-131,1.175-1.181,2.3-2.7,2.33-2.37,2.47-2.53-$ $2.59,2.67-2.72,2.105-2.109,2.145-2.150,2.197-2.205$.

[11] A. Rojek, Zasilanie trakcji elektrycznej w systemie pradu stalego 3 $k V$. KOW Sp. z o.o., Warszawa, 2012, pp. 16-19, 22-45. (in polish)

[12] A. C. King, W. Knight, Uninterruptible Power Supplies and Standby Power Systems. McGraw-Hill: New York, London, 2003, pp. 141163.

[13] S. Winder, Power Supplies for LED Driving. Elsevier Inc., Burlington, 2008, pp. 41-42, 46-51, 56.

[14] J. Saferna, Porazenia i oparzenia pradem i lukiem elektrycznym. Etiologia i pomoc przedlekarska, WNT, Warszawa 1993. (in polish)

[15] IEC Technical Report 479-1:1994 Effects of current on human beings and livestock, Part 1: General aspect.

[16] Z. Kowalski, Ekologiczne aspekty elektrotechniki, Wydawnictwo Politechniki Swietokrzyskiej. Kielce 2003, pp. 69-72. (in Polish)

[17] S. Gierlotka, "Metody badan impedancji ciala czlowieka", Wiadomosci elektrotechniczne, no. 8, pp. 18-20, 2011. (in Polish)

[18] W. Korniluk, Probabilistyczne metody oceny skutecznosci ochrony przeciwporazeniowej w urzadzeniach elektrycznych niskiego napiecia. Wydawnictwo Politechniki Bialostockiej, Bialystok 1993. (in Polish)

[19] W. Korniluk, D. Sajewicz, "Probabilistyczny model impedancji ciala ludzkiego", Wiadomosci Elektrotechniczne, no. 12, pp. 23-29, 2006.

[20] S. Gierlotka, Elektropatologia porazen pradem elektrycznym oraz bezpieczenstwo przy urzadzeniach elektrycznych. Grupa MEDIUM, Warszawa, 2015. (in Polish) 